\title{
The role of appropriation in guided reinvention: establishing and preserving devolved authority with low-attaining students
}

\author{
Yvette Solomon $^{1}$ (D) S Susan Hough ${ }^{2} \cdot$ Stephen Gough $^{2}$
}

Accepted: 9 October 2020 / Published online: 7 December 2020

(C) The Author(s) 2020

\begin{abstract}
Realistic Mathematics Education (RME) relies on the pedagogy of guided reinvention, in which opportunities for learning are created through the teacher's orchestration of wholeclass mathematical discussion towards a specific goal. However, introducing an RME approach to students who are accustomed to traditional teaching requires a substantial shift in roles, particularly with respect to the devolution of authority from teacher to student. In this study, we worked with low-attaining students, implementing RME to improve understanding of fractions. The analysis highlights how the introduction of guided reinvention is supported by extended wait time and teacher neutrality, but also by teachers' appropriation of student strategies as a basis for supporting shared authority in the joint construction of mathematical ideas. The article considers the relationship between guided reinvention, appropriation and student agency.
\end{abstract}

Keywords Guided reinvention · Appropriation · Devolved authority · Realistic Mathematics Education $\cdot$ Low attainers

\section{Background and context}

As Maass, Cobb, Krainer, and Potari (2019) point out, international evidence persistently highlights a mismatch between the innovative pedagogy advocated by mathematics education researchers and the reality of teachers' practice. However, changing practice from a focus on instruction for procedural fluency to one which prioritises the development of student agency and argumentation requires not only pedagogic change but also changes in values and beliefs.

Yvette Solomon

y.solomon@mmu.ac.uk

1 Education and Social Research Institute, Manchester Metropolitan University, 53 Bonsall Street Manchester M15 6GX UK

2 Faculty of Education, Manchester Metropolitan University, 53 Bonsall Street Manchester M15 6GX UK 
Procedural instruction is particularly prevalent in classes for low-attaining students, fed in part by low teacher expectations (Francis, Connolly et al., 2017) but also by a more subtle discourse of nurturance and dependency: Mazenod et al. (2019) report that teachers of lower attainers were concerned that students should not be "over-stretched", devising lessons around an assumed need for more repetition and rehearsal, and more teacher input rather than discussion.

As Francis, Connolly et al. (2017) note, being placed in a low attainment group generates low self-expectations on the part of students, despite the fact that they may also complain that the teaching they receive is lacking in interest and challenge (Francis et al., 2019). This recent research reflects long-standing evidence that students are aware that the procedural methods in lower attainment mathematics classes construct them as failures (Boaler, Wiliam, \& Brown, 2000). At the same time, it underlines students' agency in the classroom - they are not passive, even though the nature of the mathematics teaching they receive may construct them as such, in terms of Schoenfeld's (2018) focus on the importance of "agency, ownership and identity." Thus, enacting pedagogic change away from procedural teaching can be challenging, and not just for teachers: although they might find mathematics boring, students who are used to procedural teaching expect ownership and authority to lie outside of themselves (Amit \& Fried, 2005), and may reject an approach which asks them to explain their thinking, ask questions and take more responsibility instead of simply "learning the rules" (Brantlinger, 2014). Focussing on students from underprivileged backgrounds (who, as Francis, Archer, et al. (2017) record, are disproportionately represented in low-attaining groups), Lubienski (2002) similarly notes that discussion-based environments can simply privilege students possessing the cultural capital to engage in the required way, whereas the less-advantaged students in her study complained that "having a variety of ideas proposed in discussions confused them" (p. 114). As Lubienski concludes, however, this does not imply that reform cannot work, or can only work for some students. Rather, "the goal is to learn more about the complexity of successfully implementing meaningful instructional methods equitably [and] identify ways in which ... practices might be problematic for some students ... and also the adaptations that successful teachers make to address such problems" (p. 121).

In this article, we pursue this goal by focussing on the introduction of Realistic Mathematics Education (RME) in classes involving a particular group of low-attaining students in England - those who have failed to gain an acceptable grade in the General Certificate of School Education (GCSE) mathematics national examination at age 16. These students comprise some $30 \%$ of the annual 16-year-old cohort (DfE, 2018) and are highly likely to have been taught in lower attainment groups throughout their 11-16 schooling - "ability grouping" in mathematics is a pervasive practice in England, affecting at least $70 \%$ of students (Francis, Archer, et al., 2017). The importance of a GCSE pass grade for employment, training and further education leads many students to take resit classes, in short 9-month courses; the study reported here took place in this context, as part of an RME-based intervention designed to enhance students' understanding and engagement. We focus here on the dynamics of introducing an RME approach and its pedagogic mode of "guided reinvention" in GCSE resit classrooms, where students are unfamiliar with, and potentially more resistant to, the shift of responsibility and authority from teacher to student that it requires. Drawing on an analysis of the same lesson taught by two experienced RME teachers, we explore the strategies they use to establish the classroom norms that underpin guided reinvention. We highlight in particular the ways in which they respond to students' difficulties with initiating and sustaining mathematical discussion, and the role of appropriation in this process. 


\section{Theorising the pedagogy of Realistic Mathematics Education: Guided reinvention and the devolution of authority}

As a theory of learning, RME emphasises the role of emergent mathematics (Gravemeijer \& Stephan, 2002): students move from models of their informal activity in realisable contexts towards more formal mathematics via a process of progressive mathematisation of models (Van den Heuvel-Panhuizen, 2003). This development is supported by "guided reinvention" (Stephan, Underwood-Gregg, \& Yackel, 2014), requiring particular pedagogic practices on the part of the teacher, and corresponding student modes of participation. These include the following: social norms of communication (e.g., students listen to others' contributions, and ask questions when they disagree or do not understand; teacher avoids saying if strategies/ solutions are right or wrong); sociomathematical norms regarding the nature of mathematical statements (e.g., the class agrees on what counts as a mathematically different solution, cf. Yackel \& Cobb, 1996); the use of sketches and diagrams (e.g., students represent contexts and strategies with either realistic or more stylised drawings); and teacher modes of response and orchestration (e.g., asking for explanation/agreement, highlighting different student strategies and solutions).

These norms and practices are underpinned by a major shift of responsibility and authority away from the teacher. However, while guided reinvention relies on such a devolution of authority, the "guided" nature of the process entails at least partial retention by the teacher, exercised through their selection of, and responses to, student contributions in the orchestration of discussion. As Amit and Fried (2005, p. 162) point out, much discussion in mathematics education settings "leads to the possibility of 'shared authority' and, ultimately, a kind of authority which is non-localized, that is, in which there is no immovable division between the subject and agent of authority". This "revised authority", in which the division between agent and subject is blurred (p. 164), emphasises the role of whole-class discussion, in that it signals that students (and we would add teachers) are "participants in shaping the public domain, that is, that their private reflections and deliberations matter in building and developing the community of mathematical thinkers" (p. 165).

In order to explore these shifts, and in particular the idea of a move towards non-localised authority in the introduction of guided reinvention, we turn to Drageset's (2014) "redirecting, progressing and focusing actions" framework, which focusses on the details of "how teachers orchestrate the classroom as a response to student comments and related to content" (p. 289). As such, it lends itself to an analysis of guided reinvention teaching since it enables us to pay attention to how teachers incorporate student contributions into the discussion, but also to how intellectual authority is distributed between teacher and students. Outlined in Table 1, we see that Drageset's classification of teacher responses includes "location of authority." While this appears to run counter to the idea of non-localised authority, our interpretation and application of this aspect of the framework is that it is necessary to consider the lesson as a unit, where authority may shift between teacher and students, leading to an overall blurring of subject and agent in a jointly constructed public understanding.

Clearly, focussing actions play a key role in the devolution of authority, where the teacher's requests for students' input require them to engage fully with the mathematics and take responsibility for explaining what they are doing (Wood, 1998, p. 176). Importantly for our focus on guided reinvention, Wood highlights the teacher's responsibility for balancing student exploration with guidance, in "ways of communicating that serve to focus students' joint attention on aspects of a solution not yet fully understood but that then leave to them the 
Table 1 Classification of teachers' responses to student contributions, after Drageset (2014, pp. 297-301)

\begin{tabular}{|c|c|c|c|}
\hline Overall group & Group categories & Elaboration of teacher action & Location of authority \\
\hline $\begin{array}{l}\text { 1. Redirecting } \\
\text { actions }\end{array}$ & $\begin{array}{l}\text { a. Put aside } \\
\text { b. Advising a new strategy } \\
\text { c. Correcting questions }\end{array}$ & $\begin{array}{l}\text { Implicit or explicit rejection } \\
\text { of a student's answer and } \\
\text { direction of attention elsewhere }\end{array}$ & Teacher as authority \\
\hline \multirow[t]{3}{*}{$\begin{array}{l}\text { 2. Progressing } \\
\text { actions }\end{array}$} & $\begin{array}{l}\text { a. Demonstration } \\
\text { b. Simplification }\end{array}$ & $\begin{array}{l}\text { Solves a task alone (monologue) } \\
\text { Reduces complexity by changing } \\
\text { task, adding information } \\
\text { or step-by-step instruction }\end{array}$ & \multirow[t]{2}{*}{ Teacher as authority } \\
\hline & c. Closed progress details & $\begin{array}{l}\text { Breaks task into steps and asks } \\
\text { guiding questions with only } \\
\text { one answer at each step }\end{array}$ & \\
\hline & d. Open progress initiatives & $\begin{array}{l}\text { As (c) but questions have more } \\
\text { than one answer }\end{array}$ & Some student authority \\
\hline \multirow[t]{3}{*}{$\begin{array}{l}\text { 3. Focussing } \\
\text { actions }\end{array}$} & $\begin{array}{l}\text { a. Requests for student input } \\
\text { i. Enlighten details } \\
\text { ii. Justification } \\
\text { iii. Apply to similar problems }\end{array}$ & $\begin{array}{l}\text { Asks student(s) for more detail } \\
\text { (light touch) or justification } \\
\text { (more exacting explanation) } \\
\text { Asks student(s) to apply knowledge } \\
\text { to new/related problem }\end{array}$ & \multirow[t]{2}{*}{ Student as authority } \\
\hline & $\begin{array}{l}\text { iv. Request assessment } \\
\text { from other students }\end{array}$ & $\begin{array}{l}\text { Asks other students to assess } \\
\text { proposed answer }\end{array}$ & \\
\hline & $\begin{array}{l}\text { b. Pointing out } \\
\text { i. Recap } \\
\text { ii. Notice }\end{array}$ & $\begin{array}{l}\text { Notes important information, either } \\
\text { in streamlined or emphasised } \\
\text { summary or during dialogue } \\
\text { to guide student noticing }\end{array}$ & Teacher as authority \\
\hline
\end{tabular}

responsibility of solving the problem" (p. 176). For Drageset, while recap and notice transfer authority back to the teacher, they remain as focussing actions in that they draw students' attention to what is mathematically important. They clearly play a role in guided reinvention, where emphasis on aspects of solutions or strategies that deserve joint attention supports meaning-making.

Progressing actions present an interesting category of responses in the context of this article in that they are often engendered in situations where "a teacher is confronted with repeated failure from students [and] he or she provides more and more information in order to help" (Drageset, 2014, p. 287). As Drageset points out, a frequent strategy in such circumstances is funnelling (Wood, 1998), in which the teacher provides a series of hints as to the desired answer, removing students from the mathematical arena and placing authority completely with the teacher. However, some student responsibility for the mathematics is retained in "open progress initiatives," in which there is more than one possible answer. For Drageset, in this strategy "the teacher initiates progress but still leaves it at least partly open to the students to choose or suggest which path to follow .... Comments are also aimed at moving the process forward, but without pointing out the direction" (p. 294).

Drageset's discussion of the role of progressing actions in classrooms where dialogue or debate is stalled addresses the issues raised by Lubienski above. He argues that there may be a real role for these moves in the process of appropriation (Newman, 1990), where students are novices in both the goal (in the guided reinvention class, explaining and justifying thinking and describing actions on mathematical objects) and the procedure (comparing two fractions, for example). In this situation, the teacher appropriates the student's actions into their own interpretive system, such that "the novice ends up 
playing a role in a system he did not entirely understand when he first took the action" (p. 85). Working on the Vygotskian premise that learning is first interpersonal before it becomes intrapersonal, Newman argues that, in the presence of a gulf between expert and novice, "an appropriation process may work successfully as long as the novice is in a position to take some action that can be appropriated" (p. 93). Thus, Drageset suggests (p. 288) that "an appropriation process often includes actions that in isolation can be labeled as funneling, teacher-dominated communication, or IRE, but as part of the appropriation process these actions might be both beneficial and necessary". This distinction seems particularly useful in contexts where a redistribution of authority is to be negotiated between students and teacher, as in the lessons we explore in this article.

In what follows, we combine turn by turn application of Drageset's categories with analysis of the overall patterns of teacher communications and student participation in classes taught by experienced RME teachers. We investigate the role of appropriation in the establishment of new shared authority where students have no expectations of taking up this kind of agency in school mathematics, having always "defin[ed] themselves as outsiders with respect to mathematical discourse" (Amit \& Fried, 2005, p. 165). Hence, we explore the following research questions:

- How do teachers generate student agency in guided reinvention, even when students have little experience of taking responsibility in classroom discussion?

- What is the role of appropriation in the establishment of devolved authority?

\section{Methodology}

In this article, we focus on one particular lesson which took place as part of a larger study trialling RME across 3 educational sites offering GCSE resit courses in England. The intervention consisted of two modules designed and taught by the research team, covering the Number and Algebra strands of the GCSE curriculum and using approximately 12 and 9 hours of teaching time respectively during the 8-month-long resit course. Teaching was timed to coincide with the host institutions' schemes of work, the Number module being delivered approximately 2 months into the resit course during October/November. The "Canteen Survey" lesson occurred in the second of three 4-hour blocks in the Number module. We chose to analyse this lesson because it illustrates key features in guided reinvention, and also because it occurred early in the students' experience of RME and presented some challenges for both teachers and students. The lesson involves developing ways to compare, add and subtract fractions, building on students' informal understanding of a context of planning catering in a school canteen, based on various surveys of food preferences. As the context develops, students are asked to compare survey results from different groups and to work on informal ideas associated with the common denominator through the context of choosing (or imagining) a segmented bar which would allow two sets of survey results to be visualised and displayed, and enable meaningful comparisons. A key feature in this lesson is the emergent nature of the common denominator, which is to be generated informally by the students themselves rather than offered by the teacher (the label "common denominator" is never used). The lesson thus requires a guided reinvention approach in which the teacher needs to orchestrate debate in which students articulate and defend their 
solution strategies, particularly in relation to the context shown in Fig. 1. It represents food preferences gathered from surveys of a class of 30 students and a class of 20 students, and contains potential for conflict over comparison between 3/30 versus 3/20.

In order to illustrate a range of issues in introducing RME, we analysed the Canteen Survey lesson in two different GCSE resit classrooms, taught by two different team members, both experienced RME teachers. Lesson A took place in the Grade 12 (ages 16-17) resit class of a large comprehensive (non-selective) girls' school (22 students), and Lesson B took place in a large multi-site college of further education (13 students, ages 16-20). It should be noted that the teachers did not know the students well, having met them once for an introduction to the group, and again for the preceding lesson. All the students had recently failed to gain an acceptable pass grade at GCSE, and none had encountered RME before the intervention. The lessons were video recorded using a fixed camera focussed on the teacher. In accordance with university ethics guidance, we obtained informed consent from all students and teachers. Confidentiality was assured and pseudonyms are used throughout this article.

The classroom dialogue from both lessons was transcribed in full, with timings recorded, including pauses of more than $1 \mathrm{~s}$ (number of seconds) and inaudible passages. Because the camera was focussed on the teacher, individual student speakers are often difficult to discern, and are simply recorded as "S". When it was possible to distinguish student speakers, they are identified either by pseudonym or by number in order to show linkage between contributions.

After repeated viewing of the video material and discussion among the authors, Drageset's categories, including location of authority, were applied to all instances of teacher response to student contributions, using the abbreviation system in Table 2. In the analysis that follows, we focus not only on the coding of individual responses but also on the distribution of authority across interaction sequences in order to analyse the overall devolution of authority and the role of appropriation.

\begin{tabular}{|c|c|c|}
\hline \multicolumn{3}{|c|}{ Favourite type of food } \\
\hline \multicolumn{3}{|c|}{$\begin{array}{l}\text { Another way Jan thought she might increase the number of students eating in } \\
\text { the canteen was to have themed lunches. So one day it would be Italian, another } \\
\text { day Indian and so on. Again she surveyed students to find out what themes } \\
\text { might be popular. Students were asked to choose their favourite theme. }\end{array}$} \\
\hline \multicolumn{3}{|c|}{ Here are the results from a year 7 class and from a year 12 class: } \\
\hline Type of food & $\begin{array}{c}\text { Year } 7 \text { class ( } 30 \\
\text { students) }\end{array}$ & $\begin{array}{l}\text { Year } 12 \text { class (20 } \\
\text { students) }\end{array}$ \\
\hline Indian & 3 & 3 \\
\hline Italian & 6 & 5 \\
\hline American & 15 & 10 \\
\hline Spanish & 1 & 2 \\
\hline British & 5 & $\mathbf{0}$ \\
\hline \multicolumn{3}{|c|}{ Is Indian food more popular with the year $7 \mathrm{~s}$ or the year $12 \mathrm{~s}$ ? } \\
\hline \multicolumn{3}{|c|}{ Is Italian food more popular with the year $7 \mathrm{~s}$ or the year $12 \mathrm{~s}$ ? } \\
\hline
\end{tabular}

Fig. 1 The canteen survey slide 
Table 2 Drageset's (2014) categories with abbreviations used in the analysis

\begin{tabular}{|c|c|c|c|c|}
\hline Group & Group categories & $\begin{array}{l}\text { Abbreviation } \\
\text { in analysis }\end{array}$ & $\begin{array}{l}\text { Location of } \\
\text { authority }\end{array}$ & $\begin{array}{l}\text { Abbreviation } \\
\text { in analysis }\end{array}$ \\
\hline 1. Redirecting actions & $\begin{array}{l}\text { a. Put aside } \\
\text { b. Advising a new strategy } \\
\text { c. Correcting questions }\end{array}$ & $\begin{array}{l}\text { Put aside } \\
\text { New strategy } \\
\text { Correct }\end{array}$ & Teacher as authority & $\mathrm{T}$ \\
\hline 2. Progressing actions & $\begin{array}{l}\text { a. Demonstration } \\
\text { b. Simplification } \\
\text { c. Closed progress details } \\
\text { d. Open progress initiatives }\end{array}$ & $\begin{array}{l}\text { Demo } \\
\text { Simplify } \\
\text { Closed } \\
\text { Open }\end{array}$ & Teacher as authority & (S) \\
\hline 3. Focussing actions & $\begin{array}{l}\text { a. Requests for student input } \\
\text { i. Enlighten details } \\
\text { ii. Justification } \\
\text { iii. Apply to similar problems } \\
\text { iv. Request assessment from } \\
\quad \text { other students } \\
\text { b. Pointing out } \\
\text { i. Recap } \\
\text { ii. Notice }\end{array}$ & $\begin{array}{l}\text { Detail } \\
\text { Justify } \\
\text { Similar } \\
\text { Assess? }\end{array}$ & Student as authority & $\mathrm{S}$ \\
\hline
\end{tabular}

\section{Findings}

\subsection{Lesson A}

To contextualise the discussion of Fig. 1 in this lesson, we begin with an earlier discussion about the information on the slide in Fig. 2.

1. T: And how many people do you think preferred melon, that was their favourite fruit? [12 sec] Melon. S1, what do you think for melon [11 sec] no idea? Ok what's stopping you having a guess [10 sec] S2 any idea, melon - no? Can you see where melon is on the chart and what did you tell us S3?

2. S3: There were 200 people.

3. T: Yeah there were 200 people and this is zero and this is 200 so I'm almost 3b(ii) (Note) $\quad \mathrm{T}$ asking how many people were in this bit. So you've got the 200 people lined up there and I'm asking how many people were in this bit [indicating melon]. How many people gave that vote. Have you got an idea S5? [4 sec]

4. Imogen: If you split, if you try and split there's 200 in one section so there are 4 sections but they're not all equal so you could do... oh you mean the top one...

5. T: Yeah cos I asked about melon ...

6. Imogen: It's the smallest one out of all of them so you could guess that it's - 10? Or.. I don't know.

7. T: Well I think that's helped what she said, hasn't it. So it's split into 4 but the 4 aren't equal. And presumably when you add all these four up what should you get?

8. S: 200

9. T: Yeah. 200 cos there's 200 people altogether. S6, any ideas? [4 sec] could anybody tell me about any of the other strips what they think how many people they represent. Just raise your hand [4 sec] could anybody tell me anything about this? You said about splitting it up, Imogen [7 sec] 
(continued)

Transcript

Response type Authority

10. Imogen: Yes. I thought that ... but I'm not sure.

11. T: You think what?

3a(i) (Detail) S

12. Imogen: I think ... fractions ... but I'm not sure.

13. T: You have fractions coming in between did you say?

What do you mean by that?

14. Imogen: Erm... it's hard to explain.

15. T: Try, try, because somebody will help you I'm sure [14 sec]

3a(i) (Detail) S

16. Imogen: Erm [laughs; other Ss laugh and some talk off topic]

3a(i) (Detail) S

17. T: Holly any ideas?

18. Holly: No.

19. T: What's stopping you having ideas then?

20. Holly: Because a lot of different sizes.

21. T: Right OK. If they were all the same size how many do you think $2 \mathrm{~d}$ (Open) would be in each one?

22. Holly: 50 each.

23. T: 50. Yeah because. OK and if they were all the same size, how would they be blocked up, where would the lines be? Do you know?

2d (Open)

[2 sec ]

24. Holly: [Shakes head]

25. T: Can anybody help with that question? What Holly is saying is if these were all the same size there'd be 50 in each, cos 50 and 50 is a hundred and another 50 is 150 yeah.

26. S: So that gives you 4 sections.

27. T: Yeah there'd be 4 sections and they'd be equal. So - and they're not equal - which was your thing wasn't it [to other S] so you'd have to make an adjustment on that. [Holly nods throughout]

\section{Healthy eating}

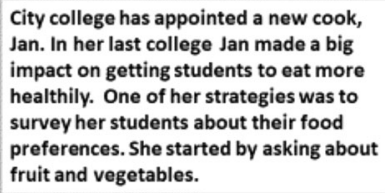

Jan made these pictures from the results she got:

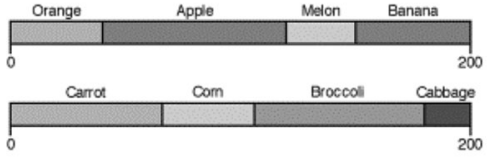

Fig. 2 The fruit and vegetable preference slide 
The patterning of this early part of the lesson appears to indicate that the students are reluctant to take responsibility for any of the required actions of hypothesising, explaining or justifying, and it seems that they are almost forcing the teacher towards type $2 \mathrm{a}$ and $2 \mathrm{~b}$ progressing actions, which would involve taking total control and doing the problem herself. Although she does indeed make a number of $2 \mathrm{c} / 2 \mathrm{~d}$ progressing actions, most are type $2 \mathrm{~d}$ (open progress initiatives, some student authority). However, her responses are mostly category 3 focussing actions, in which she persists in asking for enlightening details (type 3ai, student as authority), or points out what students say (3bi), drawing attention to their implications (3bii). While the analysis shows a dominance of teacher authority codes, two issues are noteworthy. One is that the teacher's sustained dialogues with first Imogen and then Holly involve recaps on their contributions which not only draw the other students' attention to what each has said, but also clearly indicate that these are their ideas (turns 7,9 and 25). The second issue is that wait times are strikingly long, reaching as much as $14 \mathrm{~s}$. Thus, in turn 3, we see the teacher waits for $4 \mathrm{~s}$ for an answer to her category $2 \mathrm{c}$ closed progress details question. Imogen eventually responds in turn 4 with an extended contribution in which she articulates not an answer to the question but an observation about why it is difficult to answer it, thus taking up responsibility for pushing the issue forward. She pursues this idea in turn 6 and this is followed through by the teacher, including a sequence of requests for details which locate authority with Imogen. A key contribution comes at turn 20 when Holly, selected by the teacher at turn 17, picks up the same issue of inequality which Imogen is struggling to explain. This prompts an open progress initiative in which the teacher appropriates the issue of "different sizes" to ask a hypothetical question (turn 21), followed by another in turn 23 (wait time $2 \mathrm{~s}$ ) and a recap in turn 25 which "hands the idea back" to Holly. We explore the related roles of wait time and recap in supporting an overall shared authority/responsibility in the discussion.

We turn now to the discussion around Fig. 1. The teacher first focusses on preferences for American (15/30 versus 10/20), before moving to the Indian (3/30 versus 3/20) comparison.

1. T: So out of the year 7 and year 12 who preferred American more? [4 sec] Do you see what I'm asking S8 there, have you got an opinion.

2. S8: The year $7 \mathrm{~s}$.

3. T: The year 7 preferred it more than the year $12 \mathrm{~s}$, go on tell us why.

4. S8: [inaudible]

5. T: So initially you're saying to me you thought the year 7 s presumably because $3 \mathrm{~b}(\mathrm{i})$ (Recap) $\mathrm{T}$ 15 is more than 10 .

6. [Ss all talk at once]

7. It's equal miss.

8. No it's not.

9. Because...

10. T: OK let's hear a few arguments about this. S9 what were you going to say? 3a(iv) (Assess) S

11. S9: [lengthy contribution, inaudible]

12. T: So your argument is along the lines of if you do 30 and you take off the 15 3b(i) (Recap) $T$ you're left with 15 and if you do the 20 students and you take off the 10 you're left with 10 so what's that saying.

13. [Ss all talk at once]

14. S: That's not equal

15. T: Go on S10 what were you going to say?

16. S10: Miss I think it's ... because the total of the students so it's going to be a half of them that chose it.

17. T: So you're saying it's the same because half of them in year 7 said American 3b(i) (Recap) T and half in year 12 said American 
(continued)

18. S10: Yeah

19. T: OK. Erm.. Was Indian more popular with the year $7 \mathrm{~s}$ or with the year 12 ?

20. [some Ss say year 12 , some year 7]

21. T: OK so some people are offering year 12, let's have some opinions over here. 3a(iv) (Assess) S

Erm, S11 do you think it was the year 7 or year 12 where Indian was more popular?

22. S11: Year 12.

23. T: Because?

3a(ii) (Justify) $\quad \mathrm{S}$

24. S: Because it's out of 20 whereas year 7 is out of 30 .

25. [Multiple Ss talking, one voice heard clearly] That doesn't make sense.

26. T: Let's hear another argument then, somebody said it doesn't make sense, you 3a(iv) (Assess) S must be thinking of something else. S12 what are you thinking?

27. S12: Out of 30 is more than out of 20 because there's more students.

28. T: So you're arguing it the other way round, you're saying there's more students 3b(i) (Recap) T so 3 out of more students is more than 3 out of... whereas you're [other S] are saying it's out of less students.

[side chat]

29. S: I think it's year 12 because there are less than in year 7 so basically more people want it in year 12 than in year 7.

30. T: So you're saying there's less people so having 3 out of less people you think $3 \mathrm{~b}$ (i) (Recap) $\quad \mathrm{T}$ is more.

31. S: Yes compared to those...

32. T: Well we'll come back to that.

We see that this slide creates the intended disagreements generated by the comparison of $15 / 30$ versus 10/20 (American) and, later, $3 / 30$ versus $3 / 20$ (Indian). The balance of authority in this sequence lies with the students - the teacher's responses frequently ask for student input, justification or assessment (turns 3, 10, 21, 23, 26). Most noteworthy here, though, is the extent of the teacher's neutrality. Rather than take up authority through category 1 actions in response to incorrect answers/arguments, she responds with multiple $3 \mathrm{~b}$ (i) focussing actions (Recap, turns 1-3, 10-12 and 27-28) which appear to be careful repetitions of what students have said (rather than paraphrase). Thus, she remains neutral, sustaining an overall devolution of authority despite the teacher authority of the individual responses. This neutrality also extends to her non-committal responses to correct arguments (turns 16-17, 22-24 and 29-30). We return to this issue in the discussion, but first we turn to Lesson B, which illustrates further complexities in guided reinvention in terms of the role of appropriation. 


\subsection{Lesson B}

We begin the analysis with the discussion around the slide in Fig. 1, where the teacher presents the key question of comparing preferences for Indian food between Year 12 (3/20) and Year 7 $(3 / 30$.)

\begin{tabular}{|c|c|c|}
\hline Transcript & Response Type & Authority \\
\hline \multicolumn{3}{|l|}{$\begin{array}{l}\text { 1. T: So in the year } 7 \text {, if you compare the year } 7 \text { and year } 12 \text { class, } \\
\text { do those } 2 \text { classes like Indian the same? }\end{array}$} \\
\hline \multicolumn{3}{|l|}{ 2. Ss: yeehhno } \\
\hline 3. T: Yeh or no & 3a(i) (Detail) & $\mathrm{S}$ \\
\hline \multicolumn{3}{|l|}{ 4. S1: [inaudible] one's got 30 and one's got 20} \\
\hline \multicolumn{3}{|l|}{ 6. S1: Year 12 prefer Indian [unclear, refers to 20 in the class] } \\
\hline 7. T: Because there's only 20 in the class and ...? & 3a(i) (Detail) & $\mathrm{S}$ \\
\hline \multicolumn{3}{|l|}{ 8. S1: And there's 30 in the year 7 class } \\
\hline \multicolumn{3}{|l|}{ 9. T: OK. [T is nodding] } \\
\hline 10. T: What d'you think Phil & 3a(iv) (Assess) & $\mathrm{S}$ \\
\hline \multicolumn{3}{|l|}{ 11. Phil: I think year 7 prefer ... } \\
\hline 12. T: You think year 7 prefer Indian? & 3a(i) (Detail) & $\mathrm{S}$ \\
\hline \multicolumn{3}{|l|}{ 13. Phil: Yeh } \\
\hline 14. T: Because? & 3a(ii) (Justify) & $\mathrm{S}$ \\
\hline \multicolumn{3}{|l|}{$\begin{array}{l}\text { 15. Phil: Because there's more of them, it's just more true for them } \\
\text { 16. S1: Oh yeh sorry I was getting mixed up there yeh }\end{array}$} \\
\hline \multicolumn{3}{|l|}{ 16. S1: Oh yeh sorry I was getting mixed up there yeh } \\
\hline 17. T: Because? & 3a(ii) (Justify) & $\mathrm{S}$ \\
\hline \multicolumn{3}{|l|}{ 18. [inaudible] } \\
\hline \multicolumn{3}{|l|}{$\begin{array}{l}\text { 19. S2: The percentage in year } 7 \text { would be higher [Other Ss: yeh yeh] } \\
\text { than in Year } 12\end{array}$} \\
\hline \multicolumn{3}{|l|}{ 20. S1: I got mixed up there $[\mathbf{3} \mathbf{~ s e c}]$} \\
\hline \multicolumn{3}{|l|}{$\begin{array}{l}\text { 21. S2: Even though it's the same number if you're doing it as a percentage } \\
\text { the year } 7 \mathrm{~s} \text { prefer it more than the year } 12 \mathrm{~s}\end{array}$} \\
\hline 22. T: OK, that's interesting. We'll come back to this question. & & \\
\hline
\end{tabular}

This sequence is characterised by a high level of student authority, sustained by focussing actions in which the teacher requests and orchestrates student input, not just emphasising explanations (3a(i), Detail) but also requiring justification (3a(ii), Justify) and assessment by others (3a(iv), Assess, turn 10). This latter request is important since it occurs even after the "correct" answer has been given by S1 at turns $6-8$, reinforcing the student responsibility in this sequence. As in Lesson A, teacher neutrality in response to a correct answer creates a space for incorrect answers to emerge, as in turns 11 to 15 ; this neutrality is preserved even when the subsequent discussion (turns 15-22) appears to result in an incorrect consensus, which the teacher does not evaluate beyond "that's interesting".

The next sequence picks up the same issue, after a 10-minute period during which the students have been working on representing the data on pre-printed segmented bars. Part of the RME teacher's role as the guide in guided reinvention entails identifying a student strategy that has potential in terms of (i) being accessible to other students, and (ii) supporting the emergent mathematics embedded in the materials design. In this lesson, the teacher is "lucky"; Sarah has used a strategy where she represents 3 students out of 30 on a 60-segment bar and she represents 3 students out of 20 on a 60 -segment bar (Fig. 3). The teacher shows Sarah's work to the rest of the class, and asks her to explain her solution. 
1. Sarah: I've kind of done what I've done on the first one like split it up into different [inaudible] so on the first one it's 2 [segments] per person and on the second one it's 3 [segments] per person

2. T: Ok just explain what you mean by that - that was pretty clear.

3. Sarah: It was three lines [she means segments] per person

4. T: So with the year 7, how many lines per person?

3a(i) (Detail)

3a(i) (Detail)

$\mathrm{S}$

5. Sarah: Two I think it was

6. T: Two

7. Sarah: Ok

8. T: So with year $7 \mathrm{~s}$ you used 2 lines per person, and year 12 ?

9. Sarah: 3 .

10. T: 3

11. Sarah: And then I just used 4 at the end.

12. T: So erm -4 . If she used 2 lines per person for year 7 , how many lines would she use altogether?

[some joking around takes place]

13. S: 2 lines per person so she used 8 [inaudible] so she would have used about 60 lines

14. T: Well, how many would she use for Indian?

15. S: 6

16. T: 6 yeh and how many for... So how many altogether David?

17. David: 60 [2 sec] yeh it will be 60

18. T: Because?

19. David: It's double

20. T: Yeh very good $[\ldots]$

21. T: Erm for year 12, twenty students

22. S: Forty

23. S: ... 3 lines... [correcting previous $\mathrm{S}$ ]

24. T: Erm but she used three lines per person

25. T: Why did you use three lines per person [to Sarah]

26. Sarah: Cos 20 times 3 is 60

27. T: So .... she's done 60 again 2c (Closed) T

2c (Closed) $\quad \mathrm{T}$

3a(ii) (Justify) S

2c (Closed)

$\mathrm{T}$

3b(i) (Recap) $\quad \mathrm{T}$

3a(ii) (Justify) S

3b(i) (Recap) $\quad \mathrm{T}$

The teacher spends some time asking Sarah to enlighten the details of her strategy (3a(i), turns 1-11), underlining the devolution of authority away from teacher to the student as owner of the idea. Here, the teacher's role as guide is to support Sarah in explaining her thinking, and hence steer the other students towards an understanding of her method. In turn 12, he begins this latter part of the process, largely using type $2 \mathrm{c}$ closed progress details to invite the rest of the class to rehearse the key points (again attributed to Sarah) that Year 7 are depicted with two segments each, and Year 12 with three segments each, both coming to 60 (turns 12-24).

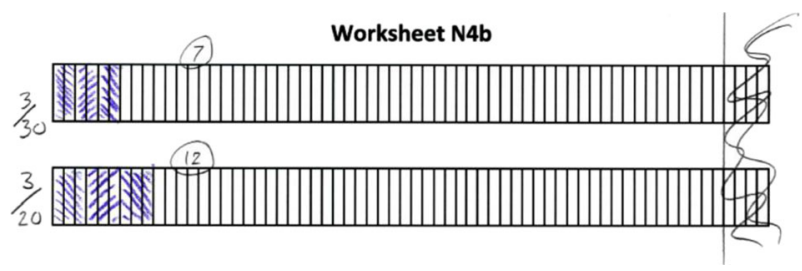

Fig. 3 Sarah's solution to the popularity of Indian food question 
Finally he asks Sarah to justify her choice (turn 25) and recaps. Like the teacher in Lesson A, although the location of authority shifts away from the students, his consistent reference to Sarah as the author of this strategy and his attempt to make the strategy joint among the class suggest that, overall, authority is shared by the classroom community. The talk then moves on to whether or not Sarah's strategy is a legitimate way to deal with the comparison:

28. T: Erm so Indian goes up to there and Indian goes up to there on the second one. 3a(iv) (Assess) S

Does that tell you much about which one is more popular?

29. Joe: No cos she's used two bars per person on the first one and three on the second one so it's the same amount of people, she's just used more lines or bars on that one so it's not - effectively it's three people and three people so it's the same.

30. T: OK. What do you think S3?

3a(iv) (Assess) S

31. S3: [clarifies which strip represents Indian on each bar].

32. T: Yeah, that's the Indian for year 12. And that's the Indian for year 7.

33. S2: It's the year 12 cos they prefer it more...

34. T: What do you think about - Joe's argument was that she tripled the year 12 3b(i) (Recap) $T$ and doubled that [year7] and that's why it's bigger. Is it fair to do that? 3a(iv) (Assess) S

35. Joe: Sir it has to be the same it has to be fair.

36. T: What do you think Sarah? Do you think it's fair to do what you've done? 3a(ii) (Justify) S

37. Sarah: No I just thought it was easier for me.

38. T: Yeah, on the bar.

39. Joe: If you'd done [inaudible] give the year 7s 60 and the year $12 \mathrm{~s} 40$ it would balance out like.

40. T: OK. But then we'd have 2 bars of different length that would take us back to $1 \mathrm{~b}$ (New strat) T the same situation of hard to compare them.

41. Ss: Yeah.

42. T: I like Sarah's method cos she's got the same length. Are we convinced that $-1 \mathrm{~b}$ (New strat) T well we're not convinced that it's fair.

3a(iv) (Assess) S

Having established Sarah's method with the class, the teacher asks a key question inviting assessment of her solution ("Does that tell you much about which one is more popular?"), beginning a sequence in which he orchestrates a discussion with most of the authority located with the students (turns 28-39). Joe is the major protagonist here in mounting an argument against Sarah's solution, supported by the teacher's almost simultaneous recapping and request for assessment in turn 34. In turn 36, he asks Sarah to defend her strategy against Joe's continued assertions in turn 35, but her response is vague ("No I just thought it was easier for me"). At this point, the teacher's attempt to orchestrate the argument between the students breaks down somewhat. Sarah does not respond to his focussing action in turn 38 ("Yeah, on the bar"), and Joe continues with his argument in turn 39. At turns 40-42, the teacher switches to two redirecting actions in which he argues that Joe's strategy does not help "then we'd have 2 bars of different length", and links this with an explanation of why he favours Sarah's strategy ("I like Sarah's method cos she's got the same length"). Although both these contributions act as an assertion of teacher authority, neither explicitly claims that Joe is wrong or Sarah is right, although clearly the teacher has broken his neutrality here. Asking the students if they are convinced, he answers his own question, acknowledging that they are not.

His next move in response to this impasse is to work through a series of progressing actions on the board in what we might ordinarily identify as a funnelling process which strips all authority away from the students; an alternative analysis however is that he is appropriating 
Sarah's method into his own interpretive system and modelling the argument that she herself has been unable to articulate in the previous sequence. That Sarah herself provides a crucial correction at turn 53 - that the Year 12 class must be multiplied by three, not two, in order to achieve comparable numbers - suggests that the teacher's demonstration has not disempowered her:

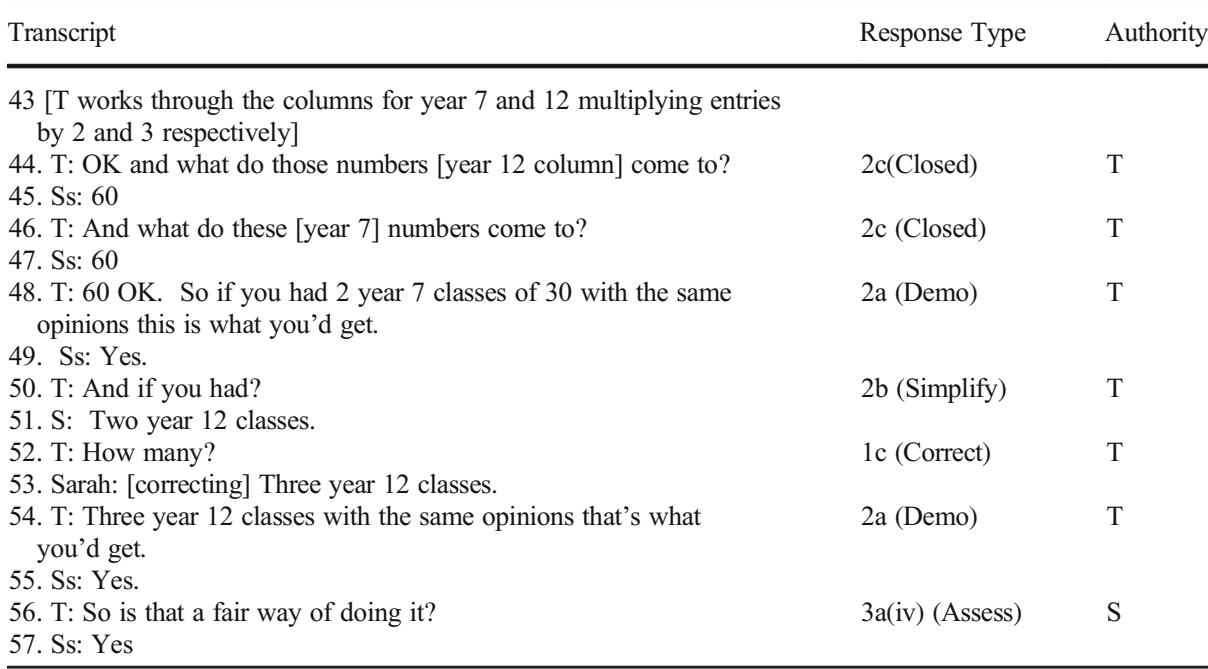

It is, of course, unclear whether or not the chorus of "yes" really indicates agreement, and this may be why the teacher then introduces a new context for the argument—opinion polls:

58. T: It's almost like what we do - you know in general elections they $1 \mathrm{~b}$ (New strat) $\mathrm{T}$ do opinion polls and they ask people. When they do a poll how many people do 3a(iii) (Similar) $\mathrm{S}$ you think they ask?

59. S: Thousands.

60. T: They do ask thousands. Yeah, erm. How many thousand do you reckon? 2d (Open)

61. S: Ten thousand.

62. T: But do you know how many people can vote? 2d (Open)

63. S: Anyone over the age of 18.

64. T: How many might that be in the UK?

2d (Open)

65. S: 30,40 million.

66. T: So they don't ask 30 or 40 million people, they ask ten thousand people. $3 \mathrm{~b}$ (ii) (Note) And then they generalise on that. And that's kind of what you've done here, you've asked 20 people here and then you've times'd by three and you've got 30 people here and you've times'd by two so we've now got something we can compare. [...]

67. Ss : [inaudible]

68. T: So let's go back to our question about Indian. So we've got 3 people from each class.

69. Joe: It's more popular in the year 12 class now. Cos if you're giving like ... one person's got 3 votes, if you times that by 3 then effectively 9 people or 9 votes have gone towards Indian. But whereas 
(continued)

Transcript

Response type Authority

for the year 7 you've only given them 2 votes so effectively

they've got 6 votes.

70. T: And this is another copy of Sarah's, [...] so for Italian, which age group $\quad 2 \mathrm{c}$ (Closed) prefer Italian?

71. Sarah: Year 7?

72. Joe: It's...no year $12 \mathrm{~s}$, year $12 \mathrm{~s}$

There is some shift back to positioning students as the authority here, before the teacher moves to a focussing action (Notice, turn 66), drawing the students' attention to the parallel between generalising from opinion polls and generating the common denominator. His recap on the original question (turn 68) encourages Joe's appropriation of the voting analogy, which he uses to correctly articulate the Indian dinner preference (turn 69), before going on to rectify Sarah's incorrect answer about preferences for Italian (5/20 versus 6/30) in turns $71-72$. As the major protagonist in the previous sequence, his contributions seem significant in view of the fact that he not only changes his earlier argument but also builds on what has gone before to articulate why. We return to a discussion of these moves below.

\section{Discussion: The role of wait time, neutrality and appropriation in devolved authority}

In this article, we have addressed Lubienski's (2002) appeal for an understanding of the complexity involved in successfully implementing pedagogy such as guided reinvention with students who may struggle with it, not because they are not capable but because they lack experience of a school mathematics that asks them to formulate and justify arguments. While this change can present a challenge for all students, regardless of prior achievement, previous research suggests that low attainers are particularly likely to struggle because of their sustained placement in "low ability" groups which construct them as in need of pedagogic "nurturance" that strips away any potential for mathematical ownership or agency. Our research questions hence explore how the teachers in this study employed particular strategies to support and develop student agency in guided reinvention, and the (somewhat paradoxical) role of appropriation in establishing devolved authority.

Our first research question- How do teachers generate student agency in guided reinvention, even when students have little experience of taking responsibility in classroom discussion?-is addressed explicitly in Lesson A, where the early phase of the lesson shows the students' hesitance to engage in discussion about the information shown on the slide in Fig. 2. As noted above, their reluctance to offer ideas has the potential to force the teacher into a funnelling routine, but her willingness to wait for an unusual length of time on several occasions has a number of roles in sharing authority in the class. It makes space for student thinking, and it also sends a message that the teacher is not always going to take the lead. More fundamentally perhaps for the guided reinvention teacher, it makes time for the teacher's own thinking as they process what students are saying, and think about how to respond. As Wallach and Even (2005, p. 410) point out, a danger for teachers is not hearing students, and acting 
instead on assumptions about their ability and how they think which lead to "overhearing, compatible-hearing, under-hearing, non-hearing and biased hearing."

The teacher's use of multiple type 3 focussing actions also enables her to avoid mis-hearing and its associated disempowerment of students. Some of these responses ask for enlightening details (3a(i), student as authority), but most involve teacher-led appropriation and recap of what students offer (3b(i)). These recaps repeat student ideas as they stand, however clumsy they may be, without replacing them with more conventional mathematical thinking. In addition to the more "social" message that students are the authors of the ideas, close hearing contributes more fundamentally to shared authority in the orchestration of joint exploration. This strategy is further supported by the teacher neutrality which is frequently expressed in $3 \mathrm{~b}$ (i) focussing actions (including in response to correct answers); in both lessons, although these recapping responses locate authority in the teacher, this strategy is central to creating opportunities for students' ownership of the debate in a classroom culture where all ideas are accepted and it is the responsibility of all participants to process each other's ideas.

Turning to research question 2-What is the role of appropriation in the establishment of devolved authority? - we have already seen how the teacher's explicit appropriation and recap of students' ideas in Lesson A appears to shift responsibility and agency in their direction. In Lesson B, we see a breakdown of the guided reinvention orchestration process, where the teacher is forced to intervene with a series of type $2 \mathrm{a}, \mathrm{b}$ and c progressing actions in order to progress the lesson. As Drageset (2014) notes, teacher-dominated actions can be beneficial and necessary as part of a process of appropriation:

it is possible that actions where the teacher keeps the intellectual authority such as advising a new strategy, demonstration, and notice, might give important contributions and support to students' struggle to develop problem-solving or reasoning competencies.

(p. 301)

Thus, in turns 43-54, the teacher appropriates Sarah's method and almost speaks on her behalf, but despite his domination, she maintains ownership in her confident correction of another student's misunderstanding. Questions will always remain for the guided reinvention teacher of how extensive the devolution of authority is in the class, and how many students have gained mathematical agency in the discussion. Still dissatisfied after this sequence, the teacher adopts yet another strategy_offering a new context - which prompts a shift of authority back to the students, and explicit uptake of the teacher's argument (and consequently Sarah's method) by Joe. As Langer-Osuna (2017) points out, we need to be aware that the distribution of authority across the student group itself may be uneven, and we can ask what the impact of Joe's quite outspoken opposition to Sarah's method earlier in the lesson might have been on her sense of agency. The analysis here suggests that the teacher's appropriation of her solution acts to encourage and support her thinking, and that of other students.

Returning to Lubienski's challenge, this study supports Mazenod et al.'s (2019) critique of a nurturance discourse which assumes that low-attaining students are not able to engage in productive mathematical discussion, and it indicates that particular strategies can support them in taking up mathematical agency despite their lack of experience of classroom environments which offer this. Central to this development are particular teacher practices which make space for student contributions and emphasise students' responsibility for, and ownership of, arguments and strategies in a context of shared or "revised" authority, as Amit and Fried (2005) suggest. Extended wait time appears essential as a means of re-setting expectations about who could be contributing to the discussion, while teacher neutrality facilitates opportunities for 
students' hypothesising and questioning. However, maintaining such devolved authority in guided reinvention can be difficult when students are, as Newman suggests, novices in both the goal and the procedure. The employment of focussing and sometimes progressing actions which emphasise student authorship of ideas and solutions appears - paradoxically - to help maintain the shift of authority away from the teacher towards at least shared responsibility. In the examples here, although teachers keep the intellectual authority in such actions, their strong focus on the students as originators of the appropriated contributions appears to provide the means by which they are able to pursue an overall process of guided reinvention which, as Wood (1998) reminds us, must leave students with the responsibility of solving the problem. How enduring this shift is is a question for further research, but this analysis underlines the subtlety of the adaptations that teachers need to make in such a context and the fine line between gains and losses in student agency, but also the usefulness of the concept of appropriation in capturing how teachers might approach the challenge.

Open Access This article is licensed under a Creative Commons Attribution 4.0 International License, which permits use, sharing, adaptation, distribution and reproduction in any medium or format, as long as you give appropriate credit to the original author(s) and the source, provide a link to the Creative Commons licence, and indicate if changes were made. The images or other third party material in this article are included in the article's Creative Commons licence, unless indicated otherwise in a credit line to the material. If material is not included in the article's Creative Commons licence and your intended use is not permitted by statutory regulation or exceeds the permitted use, you will need to obtain permission directly from the copyright holder. To view a copy of this licence, visit http://creativecommons.org/licenses/by/4.0/.

\section{References}

Amit, M., \& Fried, M. N. (2005). Authority and authority relations in mathematics education: A view from an 8th grade classroom. Educational Studies in Mathematics, 58, 145-168.

Boaler, J., Wiliam, D., \& Brown, M. (2000). Students' experiences of ability grouping-Disaffection, polarisation and the construction of failure. British Educational Research Journal, 26, 631-648.

Brantlinger, A. (2014). Critical mathematics discourse in a high school classroom: Examining patterns of student engagement and resistance. Educational Studies in Mathematics, 85(2), 201-220.

DfE (2018) SFR01/2018: GCSE and equivalent results in England 2016/17 (Revised) Subject time series. https:/www.gov.uk/government/statistics/revised-gcse-and-equivalent-results-in-england-2016-to-2017.

Drageset, O. G. (2014). Redirecting, progressing, and focusing actions-A framework for describing how teachers use students' comments to work with mathematics. Educational Studies in Mathematics, 85(2), 281-304.

Francis, B., Archer, L., Hodgen, J., Pepper, D., Taylor, B., \& Travers, M.-C. (2017). Exploring the relative lack of impact of research on 'ability grouping' in England: A discourse analytic account. Cambridge Journal of Education, 47(1), 1-17.

Francis, B., Connolly, P., Archer, L., Hodgen, J., Mazenod, A., Taylor, B., ... Travers, M.-C. (2017). Attainment grouping as self-fulfilling prophesy? A mixed methods exploration of self confidence and set level among year 7 students. International Journal of Educational Research, 86, 96-108.

Francis, B., Hodgen, J., Craig, N., Taylor, B., Archer, L., Mazenod, A., Tereshchenko, A., \& Connolly, P. (2019). Teacher 'quality' and attainment grouping: The role of within-school teacher deployment in social and educational inequality. Teaching and Teacher Education, 77, 183-192.

Gravemeijer, K., \& Stephan, M. (2002). Emergent models as an instructional design heuristic. In K. P. E. Gravemeijer, R. Lehrer, B. V. Oers, \& L. Verschaffel (Eds.), Symbolizing, modeling and tool use in mathematics education (pp. 145-169). Dordrecht, the Netherlands: Kluwer Academic Publishers.

Langer-Osuna, J. M. (2017). Authority, identity, and collaborative mathematics. Journal for Research in Mathematics Education, 48(3), 237-247.

Lubienski, S. T. (2002). Research, reform, and equity in U.S. mathematics education. Mathematical Thinking and Learning, 4(2\&3), 103-125. 
Maass, K., Cobb, P., Krainer, K., \& Potari, D. (2019). Different ways to implement innovative teaching approaches at scale. Educational Studies in Mathematics, 102, 303-318.

Mazenod, A., Francis, B., Archer, L., Hodgen, J., Taylor, B., Tereshchenko, A., \& Pepper, D. (2019). Nurturing learning or encouraging dependency? Teacher constructions of students in lower attainment groups in English secondary schools. Cambridge Journal of Education, 49(1), 53-68.

Newman, D. (1990). Cognitive change by appropriation. In S. P. Robertson, W. Zachary, \& J. B. Black (Eds.), Cognition, computing, and cooperation (pp. 84-94). Norwood, NJ: Ablex.

Schoenfeld, A. H. (2018). Video analyses for research and professional development: The teaching for robust understanding (TRU) framework. ZDM, 50(3), 491-506.

Stephan, M., Underwood-Gregg, D., \& Yackel, E. (2014). Guided reinvention: What is it and how do teachers learn this teaching approach? In Y. Li, E. A. Silver, \& S. Li (Eds.), Transforming mathematics instruction (pp. 37-57). Dordrecht, the Netherlands: Springer.

Van den Heuvel-Panhuizen, M. (2003). The didactical use of models in Realistic Mathematics Education: An example from a longitudinal trajectory on percentage. Educational Studies in Mathematics, 54(1), 9-35.

Wallach, T., \& Even, R. (2005). Hearing students: The complexity of understanding what they are saying, showing, and doing. Journal of Mathematics Teacher Education, 8(5), 393-417.

Wood, T. (1998). Alternative patterns of communication in mathematics classes: Funneling or focusing? In H. Steinbring, M. G. Bartolini Bussi, \& A. Sierpinska (Eds.), Language and communication in the mathematics classroom (pp. 167-178). Reston, VA: National Council of Teachers of Mathematics.

Yackel, E., \& Cobb, P. (1996). Sociomathematical norms, argumentation, and autonomy in mathematics. Journal for Research in Mathematics Education, 27(4), 458-477.

Publisher's note Springer Nature remains neutral with regard to jurisdictional claims in published maps and institutional affiliations. 